\author{
Andrzej Stasiak \\ https://orcid.org/0000-0001-6964-3408 \\ University of Lodz \\ Institute of Urban Geography and Tourism Studies \\ Department of Geography of Recreation \\ andrzej.stasiak@geo.uni.lodz.pl
}

\title{
ESCAPE ROOMS IN POLAND: A DEMAND-LED APPROACH USING 'NETNOGRAPHIC' RESEARCH
}

\begin{abstract}
During five years of extremely rapid and spontaneous development, escape rooms have become a permanent component of Polish urban space. At the same time, this form of recreation has gained a whole community of enthusiasts. The aim of the article is to present a comprehensive description of the people who visit escape rooms in Poland through an online survey including 718 users of lockme.pl, the largest promotional and booking portal in the country. The results have enabled the author to identify the socio-demographic features of the players, sources of information about escape rooms, user motivations, the frequency, character and course of visits, the emotions accompanying the game, as well as general opinions and evaluations of Polish escape rooms.
\end{abstract}

Keywords: free time, forms of recreation, escape rooms, experience economy.

\section{INTRODUCTION}

The dynamic and profound changes occurring in the contemporary world leave a trace in all areas of human life, including rest and recreation. One of the major causes of these revolutionary transformations is the unprecedented development of new technologies which have enabled people to create parallel, alternative worlds, in which they function outside reality. Never before has the borderline between real and virtual worlds been so indistinct. Blurring it has become the basis of creating many new, post-modernist attractions for those visiting theme parks, tourist and shopping centres, $4^{\text {th }}$ and $5^{\text {th }}$ generation stadiums, etc. (cf. Stasiak, 2019). Creating hyper-reality ${ }^{1}$ serves the purpose of satisfying the very particular needs of today's consumers: the continuous pursuit of novelty, originality and uniqueness, experiencing exciting situations and strong emotions, feeding a hedonistic imperative, engaging in continuous 'play', and getting away from everyday problems, however illusory and temporary it may be.

Post-modernist attractions of this kind include escape rooms. ${ }^{2}$ Their history is relatively short. The first were created in 2007 in Japan (Nicholson, 2015), after a few years they appeared in the USA and Europe, then spreading all over the world. Their number increased dramatically in the second decade of the $21^{\text {st }}$ century. In many countries with completely different cultures and traditions, escape rooms unexpectedly became serious competition for traditional ways of spending free time such as bowling, billiards or cinema. The wave of escape room popularity is an example of the global diffusion of innovation (Stasiak, 2016). The general business concept, as well as detailed organizational and technological ideas tested in one part of the world, were immediately implemented in others, although possibly adapted to local character and individual customer needs. The success of escape rooms resulted from an attractive market offer responding to customer tastes and the need for unique experiences, strongly saturated with emotions. On the other hand, escape rooms turned out to be highly profitable business undertakings, due to high demand keeping prices at a high level, as well as the relatively low cost of organizing the rooms and their functioning. Their popularity mostly depended on the originality of the games and not on the amount of money invested in them. 
The fashion for escape rooms arrived in Poland at the beginning of 2014 and over two years, nearly 600 were opened (Stasiak, 2016); Poland, after Hungary and Switzerland, has become one of the leaders on the European escape room (ER) market, setting standards as well as new development trends for the whole industry. A major cause of the rapid development of escape rooms in Central and Eastern Europe is the large number of abandoned, vacant premises in city centres. The historical centres of West-European cities do not offer such opportunities (Kubal, Pawlusiński, 2016).

The phenomenon of escape rooms can be analysed from two main points of view:

- on the supply side: development (growth rate, diffusion of innovation), description of the offer (room themes, game scenarios), location factors (spatial concentration), economic aspects (cost, revenues, benefits, etc.);

- on the demand side: customer segmentation, player needs and motivations, experience, opinions and evaluation.

The analysis of the origins and development of escape rooms in Poland was presented in the author's first article published in 'Tourism', in 2016 (Stasiak, 2016). The aim of this article is to present a comprehensive description of the people who visit escape rooms. Since they first appeared in Poland five years ago, escape rooms have produced a numerous community of players. Starting research in 2018, the author posed the following questions:

- Who are the escape room enthusiasts?

- What motivates them to visit the rooms?

- What emotions accompany them during the game?

- How do they rate this particular form of entertainment?

This article is a preliminary summary of the findings.

\section{LITERATURE REVIEW}

Despite the dynamic development of the ER market and its huge popularity all over the world, the issue has not been sufficiently discussed in academic articles with only several empirical works being published. The most extensive were carried out by Nicholson (2015) who provided a general description based on questionnaires filled in by representatives of 175 escape rooms in Europe, Asia, Australia and both Americas (regarding the variety of themes, room features, design models, game organization, price level, players' sociodemographic features, etc.). Based on an analysis of the survey results, Nicholson identified the most important differences between escape rooms in the USA and in Japan. However, conducted on a global scale and using small, random samples, the study was not fully representative.

Kotlar (2017) conceptualized the experiences of the customers of the two most popular ER sector companies: in New York (5 rooms) and Budapest (4 rooms). Using netnographic studies and automated content analysis (Leximancer software), on the basis of 1243 TripAdvisor opinions, he created a concept map. This demonstrated that an escape room provides visitors with new, peak, unique and fun experiences, mostly due to the difficult tasks and the social component of the game.

Similar results were achieved by Dilek \& Dilek (2018), who analysed the experiences of visitors to 33 escape rooms in Turkey, on the basis of 1079 opinions posted on TripAdvisor. The results prove that players gain original, lively experiences by solving difficult riddles, as well as working in a team (social element). The visitors were looking for novelty (authenticity), powerful sensations and emotions, hedonistic pleasure and the sense of being outside place and time.

Researchers are particularly interested in the 'flow' phenomenon, ${ }^{3}$ described by Csikszentmihály (1990) and an analysis of customer group 'flow' experiences in escape rooms was conducted in the latest work by Kotlar \& Cater (2018). The results indicate that the key determinants of the experiences related to 'flow' include group challenge, matching the skill to the difficulty level of the game, the room theme and the form of storytelling. The appearance of 'flow' has a considerable influence on willingness to participate in the next game, a tendency towards word-of-mouth communication, tightening the bond within a group of players, and even a subjective evaluation of the quality of life.

Polish publications that are noteworthy include an article by Kubal \& Pawlusiński (2016) dedicated to the escape rooms in Kraków as a component of the cultural offer of the city, used not only by residents, but also tourists, students and corporate clients. Stasiak (2016) conducted a comprehensive analysis of the ER sector in Poland. He presented the origins and development of escape rooms in 2014-2016, as well as a detailed location and description of escape rooms in 10 Polish cities.

\section{THE DEVELOPMENT OF THE ER SECTOR IN POLAND: 2016-2018}

The first escape rooms in Poland appeared in spring 2014 in Wrocław: two rooms opened by Let Me Out. The next two years brought a dramatic increase in the number all over the country and by 2016, there were already about 600 (Stasiak, 2016). Over the next two years, the increase was equally dynamic, though the trend 
slowed down slightly. According to Lockme records, at the end of 2018, there were about 1000 escape rooms in Poland (Rynek EscapeRoom..., 2018). At that time, the market had become stable for over half a year. Newly opened rooms were replacing older ones which were unprofitable or simply already used up. In the long term, experts forecast a reduction in the number of escape rooms in Poland to 800, due to the new customer segment running out (Rynek EscapeRoom..., 2018).

The reduction had already become visible in the largest Polish cities in 2018 (Table 1). Over a year, in six out of ten Polish cities, the number of escape rooms visibly decreased, and in four the number of firms as well (in two cities, it did not change). In other centres, a small increase was observed, which points to a saturation of the market. Compared to the ranking compiled two years earlier (Stasiak, 2016), there were small changes in the positions of cities: Łódź dropped from $3^{\text {rd }}$ to $5^{\text {th }}$, Bydgoszcz went up from $9^{\text {th }}$ to $6^{\text {th }}$, and Lublin replaced Białystok in $10^{\text {th }}$ place. Escape rooms should be regarded as urban entertainment with the majority functioning in the largest cities of the country. They are also strongly diversified regionally reflecting local character and trends. According to the authors of the Rynek EscapeRoom... (2018) report, Poznan is famous for rooms organized around horror and thriller themes, Bydgoszcz rooms specialize in mathematical riddles and those in Szczecin are literature-oriented. Most escape rooms of a high level of difficulty can be found in Wrocław, contrary to Kraków where easy and pleasant adventure is preferred, and focusing on experiences with tourists in mind. In Warsaw, it is important to pleasantly surprise the customer (the 'Wow!' effect) and provide them with very strong stimuli during the game.

The situation on the ER market changed drastically on $4^{\text {th }}$ January 2019, when five teenagers died in a fire in an escape room in Koszalin. The inspection conducted nationwide revealed numerous inadequacies regarding fire prevention and evacuation routes in as many as $90 \%$ of the escape rooms and as a result 69 were closed down. What is more, a new regulation was introduced, strictly defining the requirements that have to be met to run this type of activity ( $S a$ wyniki kontroli $w$ escape roomach..., 2019). Tightened safety regulations (and, consequently, higher costs) will certainly be a significant barrier in the near future, limiting rapid uncontrolled growth in the ER sector in Poland.

Apart from the quantitative increase, we should also mention the qualitative development of escape rooms in Poland. The early rooms were often built by amateurs, in only slightly adapted private flats, with a minimal outlay (5-10,000 PLN). Nowadays, modern rooms, so-called ' 3 rd generation', with multi-level sets, visual and sound effects, original props and live actors can be found. As a result, escape rooms give a full and very realistic sense of being a part of a story and travelling in 'time and space' (Rynek EscapeRoom..., 2018).

Strong competition on the ER market imposes professionalisation, which is reflected in the growing expenses of the organization of individual rooms. The cost of furnishing is significantly higher due to the use of special electronic gadgets, more and more sophisticated special effects or additional safety measures (e.g. 24-hour monitoring) indispensable in a modern escape room. This has been noticed by other firms offering special products and services required by the ER sector, not only in Poland, but also abroad.

Despite the growing costs, it is still a very profitable economic undertaking, due to the high demand for this type of entertainment. In 2017, about 2,133,000 visits were recorded in Poland, and the income of the whole ER sector was estimated at about 200 million PLN

Table 1. Escape rooms in the largest Polish cities, 2016-2018

\begin{tabular}{|c|c|c|c|c|c|c|c|c|c|c|c|c|c|}
\hline \multirow{2}{*}{\multicolumn{2}{|c|}{ City }} & \multicolumn{6}{|c|}{ Number of rooms } & \multicolumn{6}{|c|}{ Number of companies } \\
\hline & & 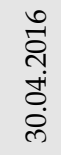 & 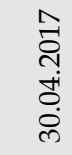 & 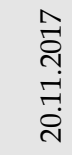 & 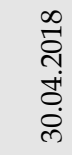 & 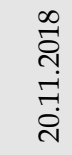 & 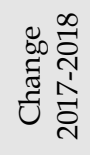 & 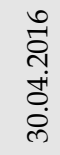 & 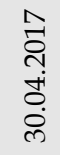 & 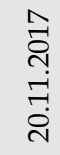 & 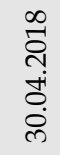 & 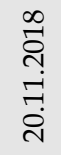 & 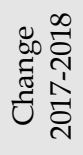 \\
\hline 1 & Warszawa & 97 & 122 & 132 & 129 & 119 & -12 & 38 & 45 & 44 & 44 & 38 & -6 \\
\hline 2 & Poznań & 49 & 80 & 104 & 73 & 85 & -19 & 24 & 32 & 37 & 35 & 38 & +1 \\
\hline 3 & Kraków & 39 & 54 & 66 & 63 & 67 & +1 & 18 & 21 & 25 & 24 & 25 & 0 \\
\hline 4 & Wrocław & 33 & 63 & 62 & 61 & 65 & +3 & 14 & 21 & 23 & 25 & 25 & +2 \\
\hline 5 & Łódź & 42 & 50 & 50 & 47 & 53 & +3 & 16 & 16 & 16 & 16 & 19 & 0 \\
\hline 6 & Bydgoszcz & 18 & 32 & 41 & 33 & 37 & -4 & 10 & 17 & 21 & 19 & 18 & -3 \\
\hline 7 & Katowice & 37 & 35 & 41 & 34 & 35 & -6 & 16 & 14 & 16 & 13 & 10 & -6 \\
\hline 8 & Gdańsk & 27 & 38 & 39 & 33 & 30 & -9 & 9 & 13 & 14 & 13 & 11 & -3 \\
\hline 9 & Szczecin & 21 & 37 & 40 & 34 & 27 & -3 & 11 & 14 & 15 & 12 & 9 & -6 \\
\hline 10 & Toruń & 8 & 20 & 24 & 20 & 25 & +1 & 4 & 7 & 7 & 6 & 8 & +1 \\
\hline
\end{tabular}

Source: author's elaboration, based on https:/ /;lockme.pl. 
(Rynek EscapeRoom..., 2018). A shortcoming of this industry is the fact that a product can in fact be used only once. The customers do not come back to the same room thus, it is necessary to look for new customers or other uses and flexible modifications of the offer. Escape rooms are willingly visited by school groups for educational purposes (mathematics, physics, literature, history) and such educational rooms are often created by museums, and even the Institute of National Remembrance in Warsaw (to familiarize the students with the complicated history of Poland after World War II). Escape rooms are being increasingly used by corporations during integration events, as part of team building activities, or even in the process of recruitment (ING Bank Śląski). Escape rooms may also be an additional tourist attraction, which enriches the offer of the city or region (cf. Kubal, Pawlusiński, 2016), enabling the visitors to discover the genius loci of a given site, or simply have some fun after a whole day of sightseeing.

Apart from ordinary tourists, there is also a growing group of escape room enthusiasts who form teams, practice regularly and travel all over Poland in search of new adventures and challenges. In March 2017, in Budapest, the first open competition for escape room enthusiasts was held, and in October 2017, Wrocław hosted the first world championship in this 'discipline' (Rynek EscapeRoom..., 2018). Local preliminaries, held in five Polish cities, included 1767 participants, forming 537 teams. The $2^{\text {nd }}$ Poland Escape in 2018 included 2750 players and 892 teams (see O poprzednich edycjach PolandEscape). The championship organizer is lockme.pl, a unique internet platform, embracing about 95\% of escape rooms in Poland which enables users to review, book and assess them. ${ }^{4}$ Based on a special algorithm, taking into account customers' opinions, a ranking of the best rooms in a city, region or country is created. Towards the end of 2017, the portal started overseas expansion: in Germany (lockme.de), Austria (lockme.at) and Switzerland (lockme.ch), and in 2018 in the USA (lock.me). In those five countries, it presents nearly 8000 escape rooms with 74,000 users, who have already posted 88,000 evaluations (lockme.pl). One of the portal's tasks is to build a community of escape room enthusiasts through the website, a Facebook profile ${ }^{5}$ and a regularly sent newsletter.

\section{RESEARCH METHOD}

The study was carried out from $12^{\text {th }}$ April to $11^{\text {th }}$ May 2018 , by means of an online questionnaire. An invitation to take part in the study was placed on the lockme.pl website, the company's Facebook profile as well as twice in the newsletters sent to subscribers. Thus, the information reached escape room enthusiasts in Poland ${ }^{6}$ but, based on the results, it is impossible to draw conclusions concerning all the users of escape rooms, but only the most active ones involved in the life of the players' community. Even though the study was not fully representative, the relatively large number of respondents allowed the researcher to describe the most common attitudes and opinions of Polish escape rooms enthusiasts.

The questionnaire included 15 questions regarding the beginnings of their involvement with escape rooms, sources of information about them, motivations to visit them, the frequency and character of the visits, as well as the emotions experienced during the game, evaluations of the rooms and prices, and any inclination to recommend this form of entertainment to others. The questionnaire also contained questions about the respondent's sex, age, education, professional status and place of residence.

At the core of the research were questions about the emotions felt during a game in an escape room. The respondents defined their emotional states, choosing among 24 answers, referring directly to Plutchik's theory of emotions (1980). The concept, developed from 1960 to 1980, assumes the existence of eight primary emotions developed naturally through evolution (the author put them into four pairs of contradictory emotions). A combination of basic emotions creates more complex emotional states.

The relationships between individual emotions are presented in a three-dimensional diagram, called Plutchik's Wheel of Emotions (Fig. 1). The horizontal

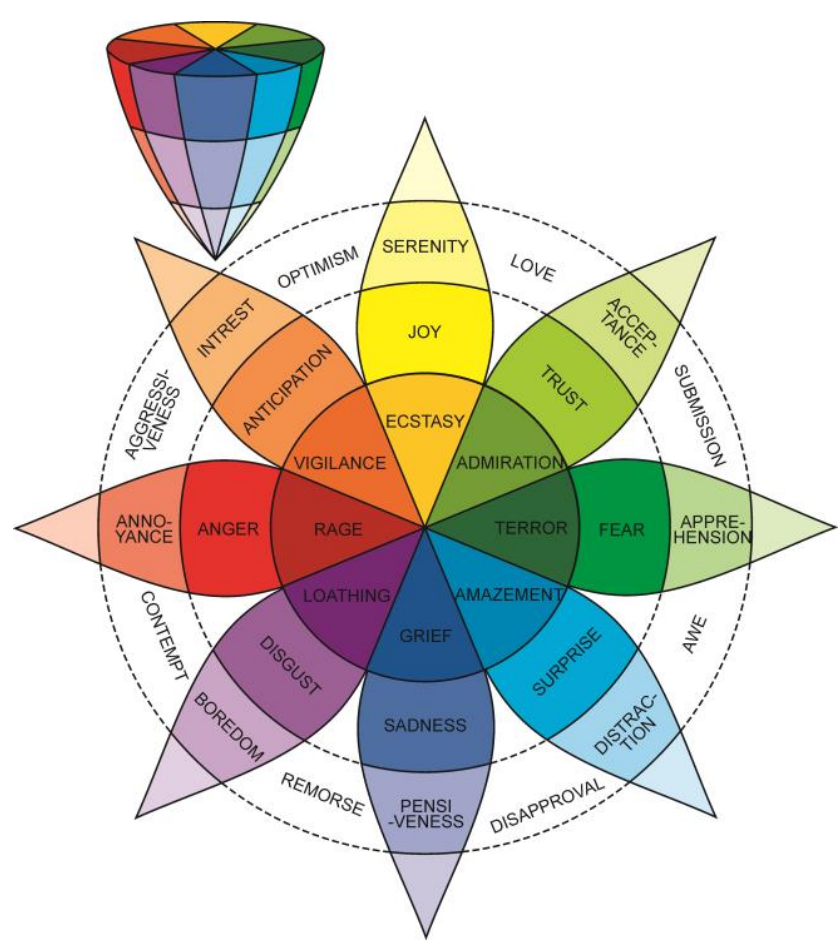

Fig. 1. Plutchik's Wheel of Emotions Source: Plutchik (1980) 
plane contains primary emotions, and the vertical one defines their intensity. After unfolding the diagram (a two-dimensional projection), free spaces are filled with dyads - combinations of basic emotions.

All in all, the survey included 725 respondents. After formal verification, seven questionnaires were excluded due to incomplete answers so ultimately, the analysis encompassed 718 respondents.

\section{STUDY RESULTS}

\subsection{RESPONDENTS' PROFILE}

The group of 718 respondents included 513 women (71.5\%) and 197 men (24.4\%). Eight respondents (1.1\%) did not provide any answers. According to ER experts, the disproportion in terms of sex is actually not so great - the proportions of male and female escape room users are more or less equal - though it naturally depends on the room theme. Thus, the larger number of women among the respondents resulted from other factors (perhaps their greater inclination to this type of research).

As regards age, the largest group consisted of young people in their twenties and thirties (Fig. 2). Over 50\% of the respondents were below 30 (20-24 - 23.8\%; 25-29 - $33.2 \%)$, and every fourth respondent in their $30 \mathrm{~s}$ (30-34 - 15.7\%; 35-39-8.8\%). Every tenth respondent $(10.5 \%)$ was below 20 . The older age ranges (above 45$)$ had only a small number of respondents $(0-1.7 \%)$. The online character of the survey certainly had an influence on such an age distribution.

Polish escape rooms enthusiasts are well educated, definitely above the national mean. Nearly two thirds of the respondents had completed higher education,

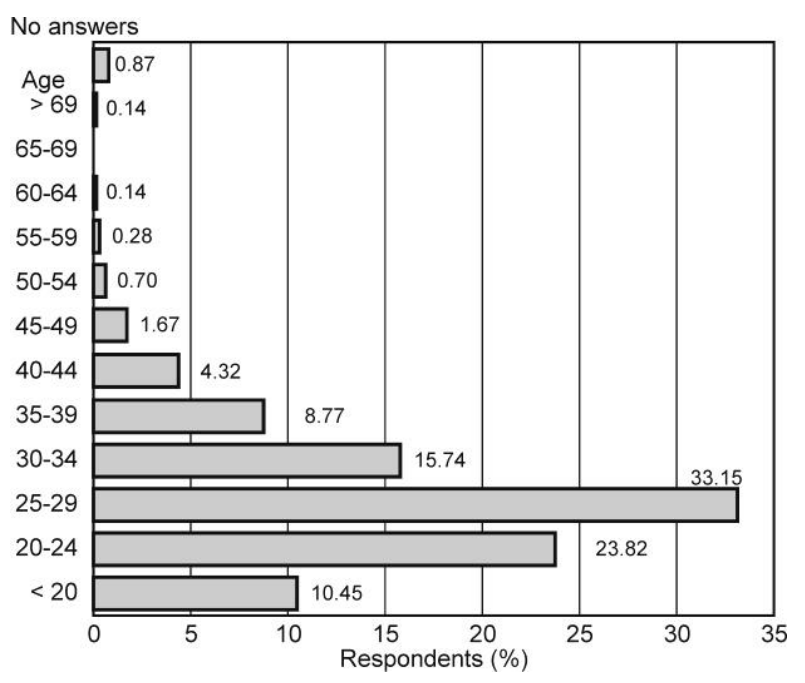

Fig. 2. Respondents' age Source: author, based on survey including $46.2 \%$ completing masters and 18.9\% bachelor. Every fourth respondent had completed secondary education $(23.1 \%$ had graduated from a secondary school and $4.3 \%$ from a further education institution), every twentieth respondent $(4.9 \%)$ had finished only a lower secondary school (gimnazjum).

The level of education corresponded to the respondents' professional status. Over $60 \%$ were white-collar workers, nearly $19 \%$ were university students, and over $8 \%$ secondary school students; only $9.3 \%$ were manual workers. Individual respondents defined themselves as unemployed, retired or pensioners.

Visitors to escape rooms in Poland are above all inhabitants of large cities and towns (Fig. 3). Over half of them $(53.2 \%)$ came from the largest urban centres in the country (populated by over 200,000 inhabitants). Every fourth respondent $(25.8 \%)$ lived in a mediumsized town $(20,000-200,000$ inhabitants) while small towns of up to 20,000 inhabitants and villages were represented almost equally (7\% and $7.7 \%$, respectively).

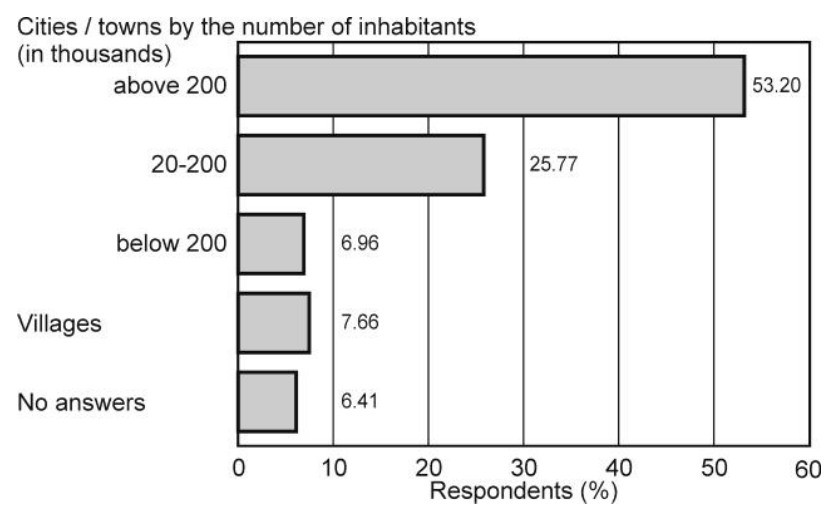

Fig. 3. Respondents' place of residence Source: author, based on survey

Despite guaranteed anonymity, the respondents were unwilling to reveal their place of residence. Only 230 people (32\%) quoted the name of the locality (Fig. 4). Therefore, a full analysis of this factor turned out to be impossible. It can be assumed, however, that they represented all regions of the country, although they mostly came from the biggest Polish agglomerations, with the largest number of escape rooms. The cities they quoted included Wrocław (34 people), Warsaw (30), Kraków (22), Poznań (17), Szczecin and Bydgoszcz (10 each).

Actually, this is not surprising. It could have been expected that escape rooms with their particular offer of mental riddles would attract these types of customer (perhaps apart from the hardly explainable disproportion between the sexes). In the light of the study, a typical user of escape rooms in Poland is a young, 20-year-old (57\%) woman $(71.5 \%)$ with higher education $(65.1 \%)$, who is a white-collar worker $(60.6 \%)$ or student $(18.9 \%)$, and an inhabitant of a large city (53.2\%). 


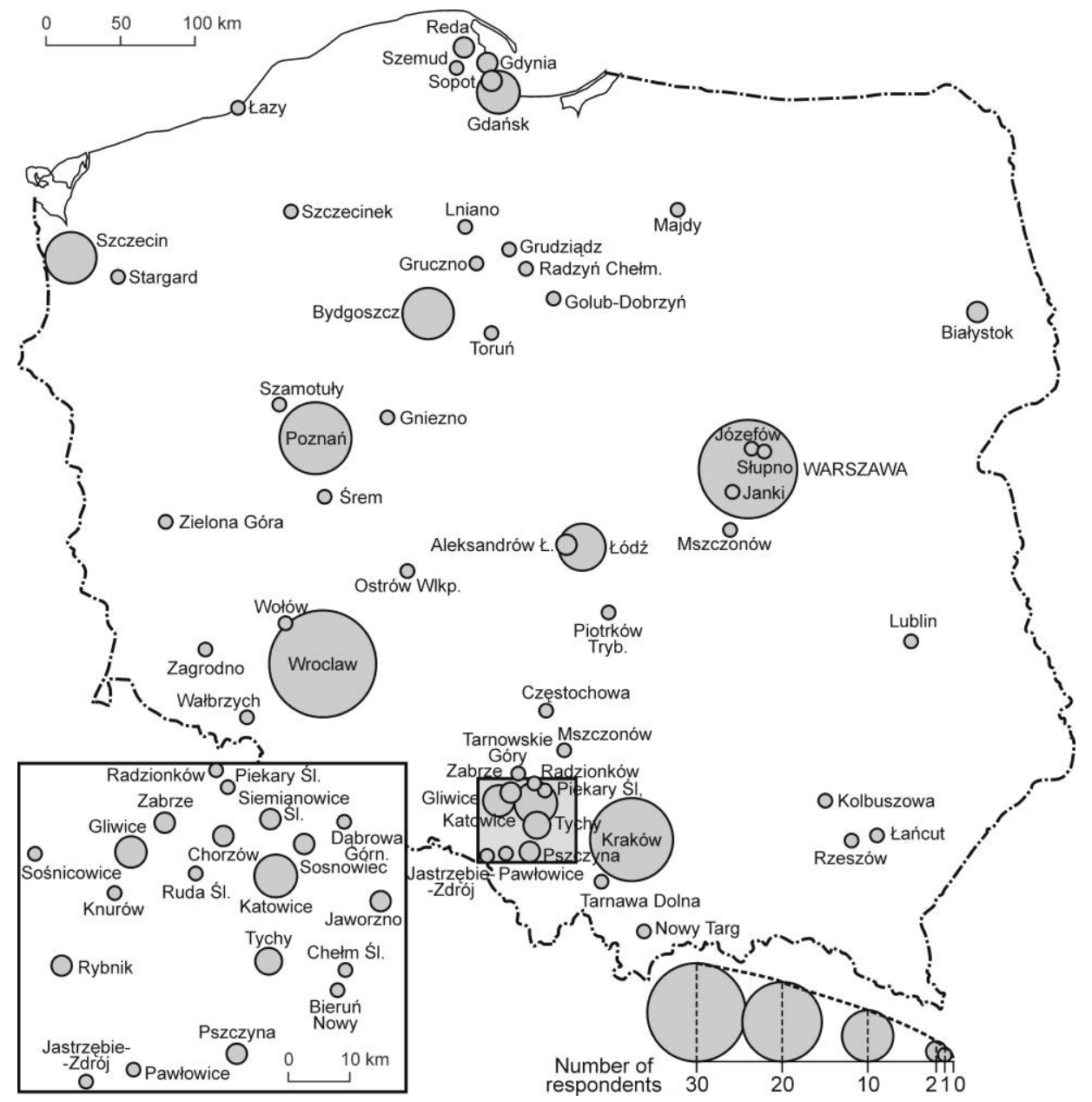

Fig. 4. Respondents' place of residence, $n=229$ Source: author, based on survey

\subsection{GAMING EXPERIENCE IN ESCAPE ROOMS}

At the time of the study, the majority of respondents already had some experience of escape rooms. Their 'adventure' usually started in 2016 (nearly 40\%), $2017(28.1 \%)$, or $2015(20.2 \%)$. Only one in 20 could be regarded as a novice who had not discovered this type of entertainment until 2018. The players who had been playing the longest and remembered the first facilities of this kind in Poland from 2014, made up under $7 \%$ of the sample. The same percentages occurred regardless of sex, age group, education or profession.

The players' considerable experience was reflected in the number of rooms visited and the frequency of visits. Only one in ten had been to an escape room 1 to 3 times, but as many as $90 \%$ at least 4 times. The most frequent answer was 'several visits' (10-19 times - 26.1\%). Nearly $30 \%$ admitted having visited escape rooms more than 25 times. That group included record-breakers, who declared 100 and 150 visits $(2.1 \%$ and $1.3 \%$, respectively).
The large number of escape rooms that appeared in Poland over a relatively short period of time resulted in a high attendance rate. The respondents turned out to be very active players who regularly visited (Fig. 5) with

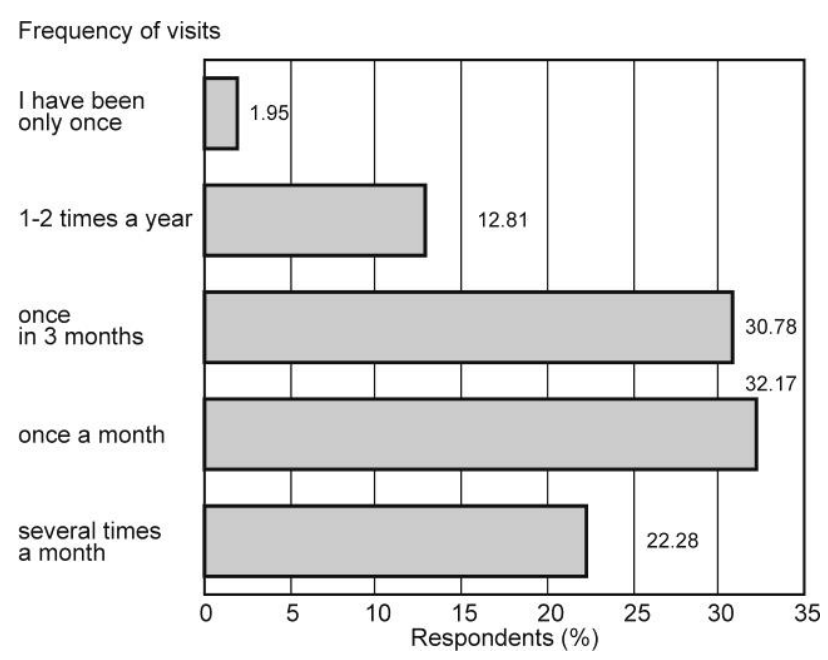

Fig. 5. Frequency of visits to escape rooms Source: author, based on survey 
nearly every third player visiting them once a month (39.1\% of men and $29.8 \%$ of women), while $30.8 \%$ at least once in three months (mostly women - 31.8\%). Visiting escape rooms once a month was stated mainly by young people (up to 34 years of age), while older respondents usually visited them once in three months. However, $22.3 \%$ chose that form of entertainment as much as several times a month. It can be suspected that this particular group included the real enthusiasts of escape rooms, seasoned players and members of established teams. Such a distribution of answers is very likely to be the result of having distributed the questionnaires among escape room enthusiasts gathered around lockme.pl. It would explain the 'overrepresentation' of the 'professionals' in relation to the less experienced players, those rare, individuals whose visits to escape rooms were stated by only about $15 \%$ of respondents.

\subsection{CHARACTER OF VISITS}

An interesting aspect are the circumstances in which the respondents visited escape rooms (Fig. 6). They took place primarily at the players' place of residence, both at weekends $(73.7 \%)$ and on weekdays $(61.3 \%){ }^{7}$ Similar proportions were observed in all groups, regardless of sex, age group, education, profession or place of residence. Visits of this type can certainly be regarded as a popular form of recreation, an attractive way of spending free time locally.

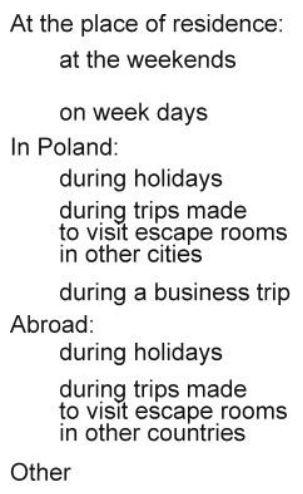

No answers

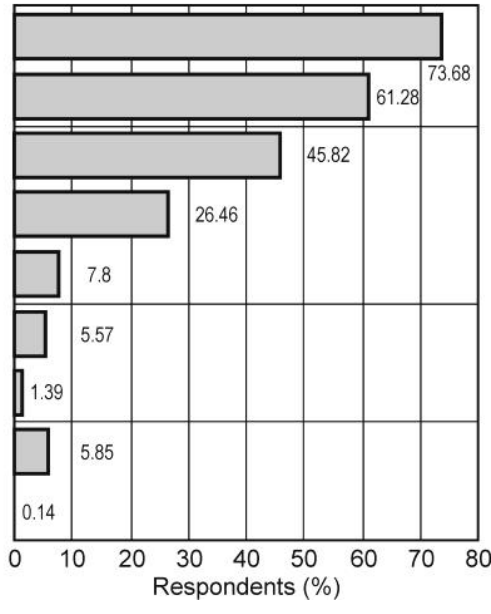

Fig. 6. Circumstances (when and where) of visits to escape rooms Source: author, based on survey

Many respondents also look on escape rooms as interesting tourist attractions which they visit during their journeys around the country. Nearly $46 \%$ stated that they visited escape rooms during their holidays in
Poland. It is interesting that over one quarter of respondents $(26.5 \%)$ travelled to other Polish cities in order to visit new escape rooms and face new challenges (33\% of men and $24 \%$ of women). They were mostly young people under $30(17.7 \%)$. Escape rooms are definitely less frequently visited during business trips $(7.8 \%)$, but the proportion of men to women is clearly visible $(10.7 \%$ compared to $6.6 \%)$. The same applies to all kinds of overseas travel (maximum 5.6\% visited escape rooms during their holidays abroad). In this last case, the language barrier was the discouraging factor.

Escape rooms are by definition social entertainment - the riddles are solved in a group; sometimes the task can be completed only when several people are cooperating. In Poland, a team usually consists of 2-5 players who have arranged earlier to meet and play together (Stasiak, 2016). ${ }^{8}$ Thus, the game is played by a group of people who know one another, which has a positive influence on the atmosphere and effectiveness of competition (e.g. due to the possibility of choosing partners who have specific skills, useful during the game). As many as $87.7 \%$ of the respondents pointed to their friends and acquaintances as playing companions (Fig. 7), dominating in all groups, regardless of sex, age, education, profession or place of residence.

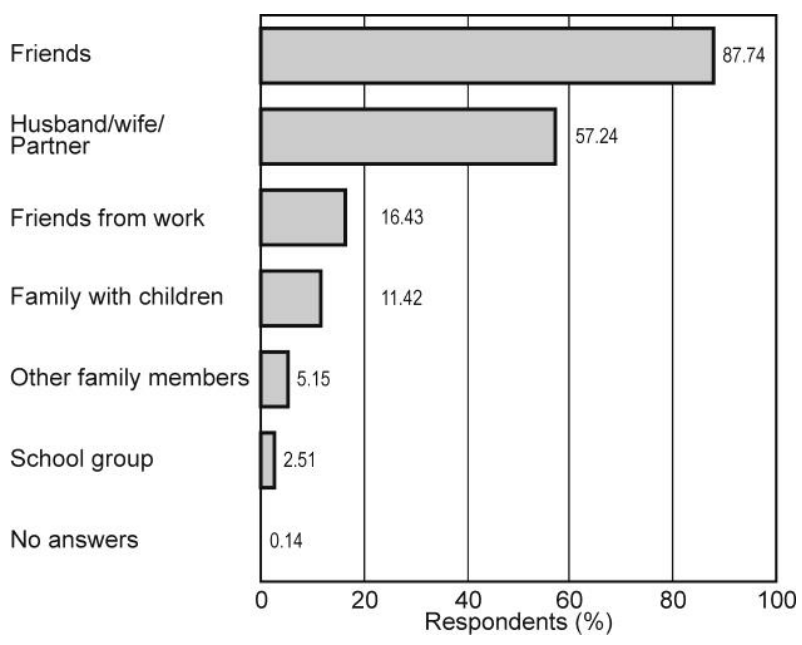

Fig. 7. Those accompanying visitors to escape rooms Source: author, based on survey

The closest family (husband/wife, partner) were mentioned much more rarely $(57.2 \%)$. It is interesting that women indicated their husbands/partners more often $(59.5 \%)$ than men did their wives/partners (52.3\%). To over $16 \%$ of the respondents, an escape room was a place where you can go with your friends from work' $11.4 \%$ stated that they visited escape rooms with their whole family, including children, while members of more distant family or school groups were mentioned very rarely. 


\subsection{SOURCES OF INFORMATION}

The main source of information about escape rooms is definitely the internet. The respondents learned about escape rooms primarily from the lockme.pl portal $(91.6 \%)$, as well as from the websites of individual rooms (55.4\%) and Facebook (36.9\%). Another major source of information was word-of-mouth. Friends' and colleagues' recommendations were followed by $51.5 \%$ of the respondents. It is interesting that they considered the opinions of their friends to be much more credible than the opinions of members of their own families (5.4\%). Friends' suggestions were followed more often by women $(54 \%)$ than men $(46.2 \%)$. Verbal recommendation was of higher value especially among 20-yearolds, people with higher education and city dwellers. For players aged 25-29, with a bachelor degree, and inhabitants of cities populated by over 200,000 people (i.e. potentially having the largest circle of friends), it was the second most popular source of information. The remaining sources (leaflets, posters, other ER portals) were of marginal importance. The escape room administrators, who have relatively modest resources for advertising, limit their promotional activity to the internet. Therefore, they usually do not use other, costlier forms of advertising, counting on the players to spread the news directly and through the social media. This seems reasonable as escape room enthusiasts often talk about their passion, share experiences and recommend the best rooms. Nearly $99 \%$ of respondents behave in this way, with $57.4 \%$ doing it very often, $33.3 \%$ - often, and only $7.9 \%$ - sporadically. $60.8 \%$ of women and $50.3 \%$ of men stated expressing their opinions about escape rooms very frequently.

\subsection{MOTIVATIONS TO VISIT ESCAPE ROOMS}

The respondents were asked to give the most important motivations for visiting escape rooms (they could choose a number of answers from the list or give their own - Fig. 8). The most frequently indicated reason was the wish to spend free time in an attractive way (79\%) and the love of puzzles and riddles (74.5\%). Over two-thirds of respondents wanted to experience something new, original, exciting $(67.3 \%)$, every sixth or seventh indicated being bored with traditional forms of spending free time, while $14.4 \%$ treated escape rooms as an alternative to just another visit to a bar. Over $50 \%$ visited escape rooms out of curiosity $(57.8 \%)$ and because they wanted to get away from everyday problems and stress (52.5\%), and $44.4 \%$ did it for social reasons (to spend time with friends). Nearly $40 \%$ pointed to a general need for rest and recreation. The respondents relatively seldom chose 'love of computer games' and 'fashion for this form of recreation' $(12.3 \%$ and $4.2 \%$, respectively). This is a little surprising because the origins of escape rooms are often sought in pointand-click and RPG computer games ${ }^{9}$ (e.g. Nicholson, 2015). One might expect a more intensive transfer of players from the virtual to the real world. After a deeper analysis, it turned out that the desire to delve into the world of computer games was strongly related to the respondents' sex. It was a motivation indicated by nearly every fourth man $(23.9 \%)$ but only by one in twelve women $(8 \%)$. The fact that the majority of respondents were women narrowed this difference in total results.

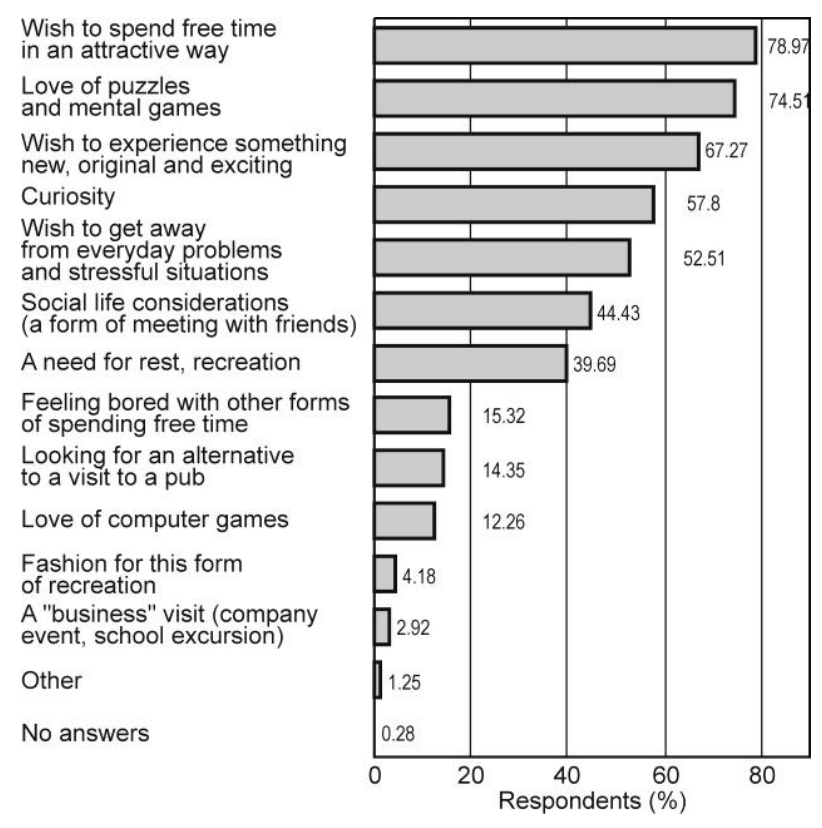

Fig. 8. Motivations for visiting escape rooms Source: author, based on survey

As regards this particular question, the respondents' preferences also depended on gender. Men more often than women pointed to the opportunity to meet with friends $(49.2 \%$ vs. $42.3 \%)$, the need to rest $(44.2 \%$ and $37.8 \%$, respectively) and 'business' visits (5.58\% and $1.75 \%)$. Women more often than men pointed to the wish to get away from everyday problems (54.8\% compared to $46.7 \%$ ).

Among the youngest respondents (under 25), the second most important motivation was the 'wish to experience something new, original, exciting'; the love of puzzles and riddles came third. In older age groups, the order of these motivations was reversed.

\subsection{EMOTIONS DURING THE GAME}

The respondents were asked to indicate the main emotions they felt while playing in an escape room. They could choose from the 24 emotional states included on Plutchik's Wheel of Emotions (Fig. 9). The predominant 

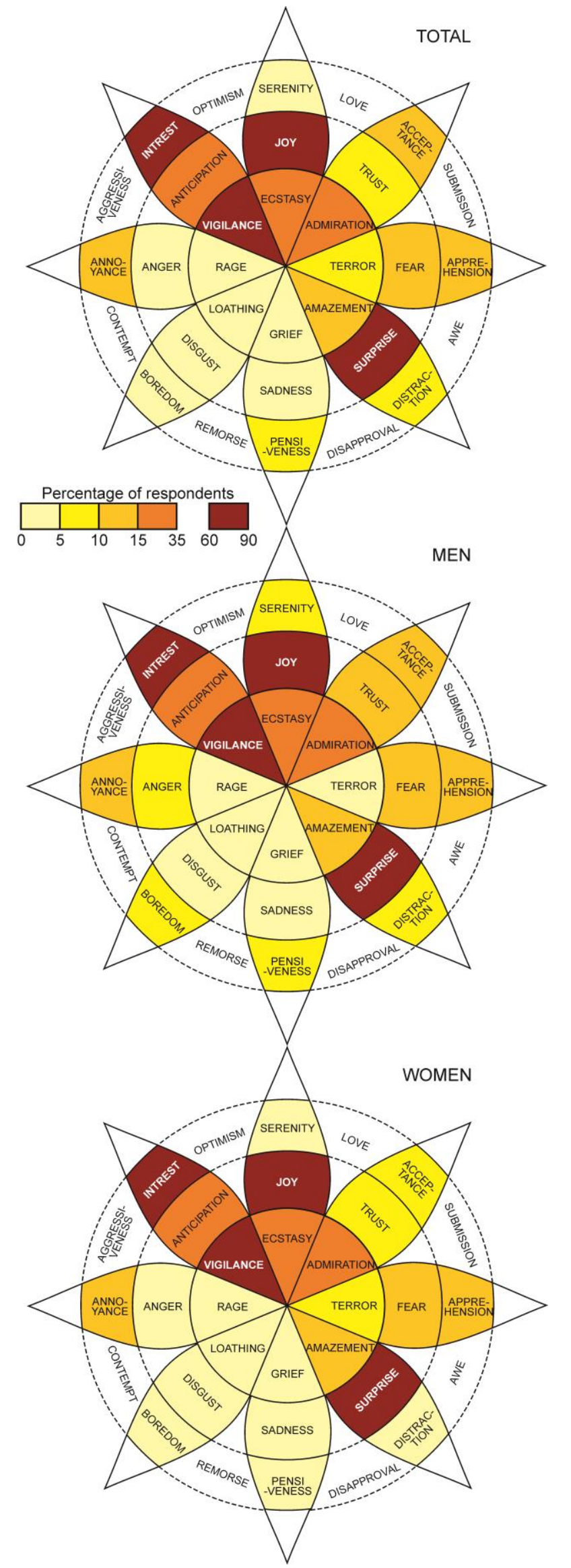

Fig. 9. Emotions felt during the game Source: author, based on survey answer was 'interest' (87.7\%). Over three quarters of the respondents felt 'joy', and two-thirds 'surprise', although equally frequently mentioned was 'vigilance'. Approximately every third respondent admitted that they felt 'admiration' or even a kind of 'ecstasy' (33.4\% and 30.8\%, respectively). Generally, the majority of emotions were positive, of medium or high intensity. Negative emotions occurred distinctly less often (though it was certainly more difficult to admit this openly in a survey). Some respondents mentioned: 'apprehension', 'fear' and 'annoyance' while a few mentioned 'distraction', 'terror', 'anger' and 'boredom'. Occasionally, the respondents mentioned 'rage', 'disgust' or 'loathing'. It is easily noticeable that a smaller incidence of negative emotional states co-occurred with their lower intensity.

The emotions felt while playing a game are certainly highly individualized, depending, above all, on personal features. Regardless of place of residence, professional status, education or age, the four most frequently reported emotions were 'interest', 'joy', 'surprise' and 'vigilance' (mentioned in this particular order in nearly all groups). Generally speaking, this also concerns the division of respondents according to gender, though in this particular category the differences were more visible, especially as regards emotions which were mentioned less frequently. The percentage of men indicating 'anticipation' was twice as high as women (33\% and $16.2 \%$, respectively) while women more often than men mentioned 'surprise' (68.6\% compared to $61.4 \%$ ). They also turned out to be more emotional ('joy' - 79.3\%, 'ecstasy' - 3.8\%) but men were more inclined to feel 'admiration' (38.1\%) and 'pensiveness' $(9.1 \%)$. In these last cases, the differences between sexes were not significant, ranging from $5 \%$ to $6 \%$.

As the respondents were asked only about their general feelings, it is impossible to indicate the causes of those emotions (both positive and negative). They may result from the room's theme (e.g. horror), its design, game scenario, sudden situations (e.g. technical problems) or the final result of the game (success or failure). It is certain, however, that an escape room game evokes extremely strong emotions whose intensity was described on a scale from 1 (weak) to 10 (extreme). The arithmetical mean for the whole sample was 7.7. The most frequently selected ratings were ' 8 ' (32\%) and ' 7 ' (28.1\%) while nearly every fourth respondent gave the highest scores (' 9 ' and ' 10 '), signifying the highest level of emotion. For $12 \%$ of the respondents, their emotions were fairly cautious, but they still fitted into the upper half of the scale (6 points). Only some individuals placed their emotions in the lower half of the scale, rating them as average or weak (3-5). None indicated the minimum level of emotion (1-2). It can be assumed, thus, that escape rooms do not leave anybody who enters them indifferent. 


\subsection{EVALUATION OF ESCAPE ROOMS}

The sources of players' emotions and satisfaction are indirectly suggested by the answers to the next questions in the survey, on what they liked best about escape rooms. Nearly all respondents $(93.2 \%)$ pointed to the tasks and riddles which had to be done or solved in order to escape from the room (Fig. 10), especially if they were original (unique), varied (within one game), surprising, required creativity, etc. Equally important were elements strictly connected with the puzzles: the room theme $(81.3 \%$ - this feature was most often indicated by the youngest players, under 20 secondary school students), the interior design $(75.8 \%)$ and the storyline of the game $(57.4 \%)$. Over $45 \%$ of the respondents mentioned special effects, and every third stressed the important role of the escape room staff (so called 'game masters', introducing the players to the story, explaining the rules of the game and helping to solve the puzzles).

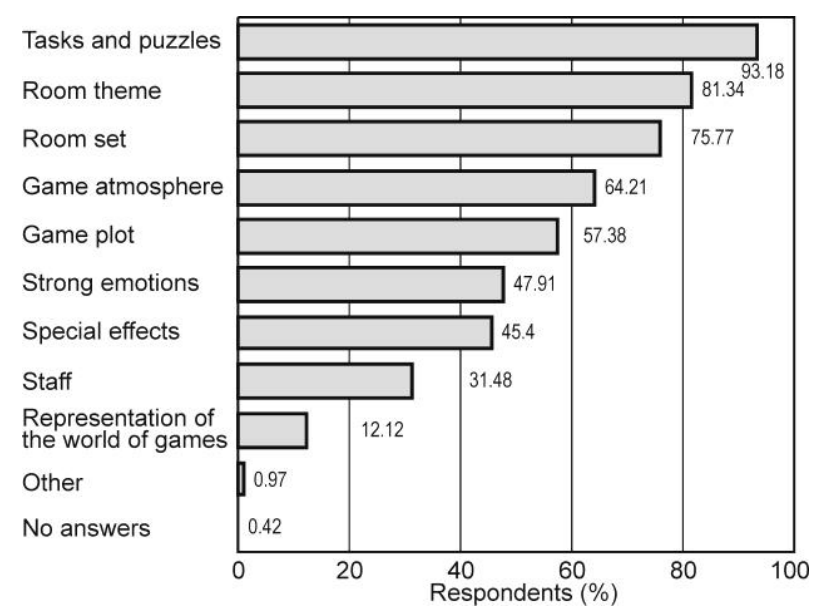

Fig. 10. Answers to the question: 'What did you like best about the escape rooms?'

Source: author, based on survey

All the elements build the atmosphere of the game, appreciated by two-thirds of the escape room users (70.1\% of men and $62.2 \%$ of women). Nearly half of the the respondents $(47.9 \%)$ valued the strong emotions experienced during the escape from the room (here, we can observe the biggest advantage of women over men: $49.7 \%$ compared to $42.6 \%$ ). The boost of adrenalin results from a full involvement in the game, immersion in an imaginary reality, competition, and the growing pressure of passing time. It is interesting that relatively few respondents (12.1\%) liked the modelling of escape rooms on computer games or on films. This answer was definitely given more often by men $(15.7 \%)$ than women $(10.5 \%)$. Although it corresponds to answers concerning motivations for visits, it can also be the effect of technical problems, making it difficult to put such 'mystification' into real life.

\subsection{PRICES OF ESCAPE ROOM GAMES IN POLAND}

Before starting an analysis of prices at escape rooms, it is necessary to present several terms. Polish standards provide that:

- the price refers to one game, not to one player;

- the game is usually played by 2-5 players (increasing the size of the team, if it is possible, involves a higher price);

- a typical game usually lasts 45-60 minutes - shortening or prolonging the game increases the price;

- it is assumed that the cost of a game played by one person should be comparable to the price of a cinema ticket (one game $=4-5$ tickets).

The analysis conducted by Stasiak (2016) shows that the prices of escape room games in Poland are several times lower than in West European countries or the USA. In 2016, the average price of a game in 10 Polish cities was under 94 PLN. It was most expensive in Warsaw (120.61 PLN), Łódź (over 110.60 PLN) and Wrocław (105.64 PLN).

However, based on the Rynek EscapeRoom... (2018), it can be concluded that in the last two years, the prices of escape rooms have significantly increased. In 2018 in Warsaw, it was, on average, 147.33, followed by Wrocław with 130.13 PLN, and Kraków with 119.42 PLN. All together, there were 32 cities where the average price for an escape room game was 100 PLN and over. The most expensive locations included the largest cities and tourism centres in Poland. Considering the low inflation rate, the increase in prices should be related, above all, to the high and constantly growing demand for this type of entertainment.

New light has been shed on the problem of prices by the results of the survey. The respondents were asked for an evaluation of the level of prices at Polish escape rooms. Over half $(51.5 \%)$ responded that it was appropriate (including $54.8 \%$ of men). Nearly the same number of respondents (but including more women) claimed that the prices were too high $(42 \%$ - rather too high, 5.3\% - definitely too high). Only a few people considered the prices to be 'rather low'; nobody described them as 'definitely low'. Those opinions are not surprising - customers usually think that they pay enough or even too much.

The next question concerned spending a larger amount of money for an even more exciting game. Nearly every fourth respondent was not willing to pay more (2.2\% - definitely not, $20.8 \%$ - rather not). A similar percentage $(23 \%)$ had not formed an opinion yet. However, more than a half were willing to pay extra: $40.4 \%$ - rather yes, $14.6 \%$ - definitely yes. In nearly all groups of respondents divided according to age, education, professional status or place of residence, the predominant answer was 'rather yes'. Thus, the demand for this kind of entertainment has substantial prospects 
for development. There is a numerous group of customers, for whom cost is not the most important element. They are ready to accept an increase in the price of escape rooms, provided they are offered a more attractive game, full of exciting experiences. Naturally, those were only declarative statements - it is hard to predict whether and to what extent they will be reflected in actual purchase decisions.

\section{CONCLUSIONS}

The emergence and development of escape rooms reflects general cultural processes and the transformations occurring in contemporary societies all over the world. They mostly concern young people who willingly escape from the professional stress and the problems of everyday life to an artificially created, alternative reality. The trend is becoming increasingly strong, as it involves pleasant, multisensory experiences, extremely intense emotions and a feeling of experiencing something special. In this sense, escape rooms should be viewed as a model product of the experience economy: a well thought-out and meticulously planned (interior design, game scenarios, riddles, etc.) product, which engages all senses, absorbs the customers, takes them to a different reality, enables them to participate interactively and co-create their own and other players' experiences (Stasiak, 2016, 2019).

As a relatively new phenomenon on the leisure market, escape rooms have not been thoroughly investigated yet. The studies conducted by the author certainly do not fill the whole cognitive gap, but they provide a lot of information useful in the evaluation of the current condition of the ER industry in Poland, as well as help to make a general description of the players' community.

It seems that after several years of extremely dynamic and uncontrollable growth, the escape room market in Poland has already matured. This mainly applies to the largest cities, where the number of escape rooms has reached a high level, and in some cases has even started to fall again. It will be definitely more difficult for new firms to start the ER business there. Mediumsized cities (e.g. Elblacg, Płock, Radom, Sosnowiec, Wałbrzych) as well as some larger tourism centres (e.g. Gniezno, Kołobnrzeg, Krynica, Łeba, Sandomierz) still have some capacity for new rooms. Heavy competition should result in further increase in the attractiveness of the escape rooms and the quality of service. The generally positive prospects for the whole ER industry were drastically changed by the tragic fire in Koszalin. Further development of this market is in question. In response to the crisis, the largest companies started to work on establishing proper safety standards for escape rooms. They will certainly involve higher running costs, but the real challenge will be to overcome the negative image implanted by the media in the general public awareness.

The study results confirm earlier assumptions concerning enthusiasts of Polish escape rooms. It is a community of young people (20- and 30-year-olds) who have completed higher education, white-collar workers and students, all living in large cities. The population under study turned out to be deeply involved in their passion: the respondents visited escape rooms often and regularly, frequently travelling to other cities in order to visit new facilities. No relationship between the respondents' personal features and their behaviours, emotions or opinions was observed, probably due to the significant homogeneity of the study sample. Nevertheless, as regards some questions in the survey, clear differences could be observed for example between the answers provided by women and those given by men.

A particularly interesting aspect are the motivations of people visiting escape rooms, as well as the benefits they gain from participating in a game. The motivations they mention can be divided into several basic groups. The largest (and possibly the most important) one includes boredom with traditional forms of recreation, a wish to spend free time in an attractive way, as well as search for a new, original exciting offer. The next group of motivations includes the love of riddles and mental games, but not solely computer games. Escape room users are not computer geeks, devoid of social and socializing competences (Corkill, 2016, after: Kubal, Pawlusiński, 2016). Other significant motivations include interest, escapism and social considerations.

The incredible success of escape rooms lies in the presence of strong, mostly positive emotions in the games. The feelings quoted by the respondents most often included interest, joy, surprise, vigilance, admiration, or even ecstasy. Negative emotions appeared definitely less often and were less intense, but generally the emotions evoked by escape rooms were extremely intense. The majority of respondents placed them in the upper half of the scale.

However, emotional involvement is not the most important element guaranteeing players' satisfaction. In the general evaluation of the escape rooms, a key role is played by the tasks to do and the riddles to solve. They should be original, varied and surprising. Equally important were the room theme, interior design and the game storyline, as well as special effects. All these elements build the overall atmosphere of the game, which eventually decides the final satisfaction of the customers. It is worth mentioning that over $50 \%$ of the respondents would be willing to pay a higher price for a more interesting and more emotional game. 
The findings lead to interesting conclusions, but because the sample is not representative, they have to be approached with a certain caution as they do not represent the whole population of ER visitors in Poland. Drawing far-reaching conclusions is also difficult due to the lack of similar research in Poland and abroad. Thus, for the time being, it is not possible to conduct a comparative analysis and establish to what extent Polish escape room enthusiasts resemble players in other countries and how they differ. Let us hope that the situation will change in the near future.

\section{ENDNOTES}

${ }^{1}$ In this case, hyper-reality means imitating real, or even "more real than real" experiences (Williams, 2002, p. 190).

2 Some researchers view them as typical simulacra (Dilek, Dilek, 2018).

${ }^{3}$ The name highlights the special state of mind between satisfaction and euphoria, caused by total immersion in an activity (in this case - playing a game in an escape room). Focusing on the task for the pure pleasure of doing it leads to a feeling of excitement, elation, or even ecstasy. Characteristic features of 'flow' include: lack of self-awareness, loss of sense of time and total freedom from fear or apprehension.

${ }^{4}$ Using a basic account version, the portal posts business cards free of charge. A $15 \%$ fee is charged for enabling more advanced functionalities, including being a part of the lockme.pl booking system.

5 In March 2019, the company's profile was visited on Facebook by over 8,400 people, and groups administered by the website - "Właściciele Escape Room Polska" and "Fani Escape Room" - had 367 and 2289 members, respectively.

${ }^{6}$ As the survey questionnaire was prepared only in Polish, the study did not include foreigners.

7 With this question it was possible to choose more than one answer which is why they do not total $100 \%$.

8 This way of forming a team, however, is not popular all over the world, e.g. in Asia as well as North and South America, the teams consist of more players and are formed on the spot from people who do not know one another (Nicholson, 2015).

${ }^{9}$ A computer role-playing game - a feature game in which the player controls a character moving around a fictional world.

\section{BIBLIOGRAPHY}

Csikszentmihalyi, M. (1990). Flow: The psychology of optimal experience. New York: Harper and Row.

Dilek, S.E., Dilek, N.K. (2018). Real-life escape rooms as a new recreational attraction: The case of Turkey. Anatolia, 29 (4), 1-12. DOI: 10.1080/13032917.2018.1439760.

Lockme Deutschland. Retrieved from: https:/ / lockme.de (28.03.2019). Lockme Österreich. Retrieved from: https://lockme.at (28.03.2019).

Lockme Polska. Retrieved from: https://lockme.pl (28.03.2019).

Lockme Schweiz. Retrieved from: https:/ / lockme.ch (28.03.2019). Lockme United States. Retrieved from: https:/ / lock.me (28.03.2019).

Kolar, T. (2017). Conceptualising tourist experiences with new attractions: the case of escape rooms. International Journal of Contemporary Hospitality Management, 29 (5), 1322-1339. DOI: 10.1108/IJCHM-12-2015-0687.

Kolar, T., Čater, B. (2018). Managing group flow experiences in escape rooms. International Journal of Contemporary Hospitality Management, 30 (7), 2637-2661. DOI: 10.1108/IJCHM-032017-0152.

Kubal, M., Pawlusiński, R. (2016). Escape rooms - nowe zjawisko w przestrzeni turystycznej Krakowa. Annales Universitatis Paedagogicae Cracoviensis Studia Geographica, 221, 244-258.

Nicholson, S. (2015). Peeking behind the locked door: A survey of escape room facilities. White paper retrieved from: http:// scottnicholson.com/pubs/erfacwhite.pdf (28.03.2019).

O poprzednich edycjach PolandEscape. Retrieved from: https:// polandescape.com/poprzednie-edycje (28.03.2019).

Plutchik, R. (1980). Emotion: A psychoevolutionary synthesis. New York: Harper and Row.

Rynek EscapeRoom w Polsce. Raport (2018). Retrieved from: https:// lockme.pl/userfiles/files/RynekERwPolsce_raport.pdf (28.03.2019).

Sa wyniki kontroli w escape roomach. 9 na 10 z nieprawidłowościami. Sa nowe przepisy (2019). Retrieved from: http://wiadomosci. gazeta.pl/wiadomosci/7,114883,24352499,sa-wyniki-kontroliw-escape-roomach-dziewiec-na-dziesiec-obiektow.html\#s= BoxOpImg1 (28.03.2019).

Stasiak, A. (2016). Escape rooms - a new offer in the recreation sector in Poland. Tourism/Turyzm, 26 (1), 31-47. DOI: 10.1515/ tour-2016-0003.

Stasiak, A. (2019). Przestrzeń turystyczna jako przestrzeń doświadczeń. Prace i Studia Geograficzne, 64.1, 61-87.

Wiliams, A. (2002). Understanding the hospitality consumer. Oxford: Butterworth-Heinemann.

Article received:

10 April 2019

Accepted:

13 May 2019 